\title{
OUT OF THE CLINIC INTO THE HOME: CONTROL AND PATIENT-PHYSICIAN COMMUNICATION
}

\author{
A.NDREA SANKaR \\ School of Public Health. University of Michigan. Ann Arbor. MI 48109. U.S.A.
}

\begin{abstract}
The communication of information between patient and physician is a difficult and often flawed undertaking. Although the patient may be more immediately aware of dissatisfaction with the results, the presence of incomplete or inaccurate information will ultimately affect the physician's ability to function and the quality of care he can deliver. This is an especially important problem in chronic illness where the social, psychological and environmental factors which may impinge on the illness often cannot be identified or verified by laboratory tests.

The physician"s need to maintain control and hence power over the patient has been suggested as an explanation for these communication difficulties. This paper examines how the home setting influences physician control by including information about the patient and his disease which the clinic context actively excludes. It argues that the loss of control which physicians experience affects communication between patient and physician and thus the quality of information obtained in that communication. and further that the information gathered is important in the care of the long term chronically ill patient.
\end{abstract}

This article examines the influence of setting on patient-physician communication. It will analyze the impact of a non-clinical setting-the home-on the control physicians traditionally exercise over that communication. I will be concerned not only with a systematic explication of the role of context but will also argue that the nature of information which emerges from this communication is particularly salient in the long term management of the chronically ill patient.

\section{CONTROL AND COMNILNICATION}

It is well established that within the clinical context physicians exert control over communication with their patients. This is done in many ways, i.e. through body language [1] or the use of technical jargon [2]. There are several explanations for this dynamic. Cartwright [3] argues that it results from a difference in social status. Parsons [4] hypothesizes that the exercise of control is necessary for the physician to maintain power over the patient. Access to information about another is one mark of power [5] and the asymmetry between professional and lay understandings of disease creates an inherently differential access to information. Such power is believed to have a therapeutic logic, the less said the more all knowing the physician appears and hence may be invested with a symbolic power to heal. Fox [6] developing Parson's theories posits a more pragmatic explanation. She argues that the practice of medicine involves a considerable amount of uncertainty. Control over information may serve as a talisman obfuscating the physician's uncertainty and assuring physician and patient alike of the physician's ultimate power over his disease. Such control also, according to Emerson [7], helps maintain a face-saving distance in potentially embarrassing clinical encounters, such as the gynecological examination.

Yet this control also seriously inhibits the flow of information and often leads to patient dissatisfaction [8]. Because control appears to be so embedded in the dynamics of patient-physician communication. its loss, when such occurs, is sharply noticeable to physicians, sometimes to the point of engendering consternation. Its loss also, as we shall see, has important implications for treatment. In a study designed to assess the effects of a home visiting experience on medical students' attitudes toward the chronically ill elderly, informants' responses consistently centered around the issue of control, its loss and the effect such a loss had on treatment and on the physician's relationship with their patient. The 'loss of control' which is how many students chose to describe the experience affected their perceptions of themselves as physicians, of the appropriateness of their role, of chronic illness, and their attitudes toward elderly patients.

\section{THE PROGRAM}

The Home Care Program where this research was conducted was part of an 8-week Family Medicine clerkship which treated patients referred from Internal Medicine. It involved at least one afternoon a week of student time. Teams of fourth year medical and pharmacy students were assigned primary care responsibility with attending supervision for two or three seriously ill homebound patients. The teams visited the patients at least once a week in their homes, more if it was medically necessary, and were on 24 hour call. A staff consisting of a medical director. nurse. social worker and pharmacist oversaw the program. The research on which this work is based was conducted over fourteen months during a period from March 1980 to August 1981. During this period the researcher attended all staff meetings and accompanied four teams each clerkship on their regular home visits and on emergency visits whenever possible. Teams were chosen by their assignments to the patients who were followed throughout the research. Students were interviewed at length before and after the 8 week clerkship ( $N=18$ medical students). Detailed observational notes and casual conversations 
during all home visits were recorded in writing and later transcribed. The work which follows examines and describes the students experience and analyzes the sharp change it produced in many students.

\section{LOSS OF CONTROL}

Control over communication and hence the amount and kind of information transferred was, for my informants, the most startling difference between treating patients at home and treating them in the clinic or inpatient setting. Control affected the kind of information they obtained in the home in two main ways. Because the students had less control over communication between themselves and the patient, it was not always possible to get the kind or amount of information they were accustomed to obtain. Concrete and specific aspects of the medical encounter were altered by the home context. Actions taken for granted in the clinic were suddenly points of negotiation within the home. The degree of undress was one of the most immediate and starting differences. Instead of initially encountering the patient semi-nude on the examining table, students found patients either fully dressed or in robes sitting or lying down, usually in the living room, occasionally in a bedroom. Often other family members or friends were present. How many clothes were removed, when and where had to be discussed. As one student commented about a 99 year old patient: "She was wanting to maintain, to at least some degree, too much control over her own exam. You could only undress her so far and no further". Undressing the patient in the intimacy of the home proved difficult, sometimes embarrassing and often humorous. With no nurse assistance the students had to help elderly women with their bras or support hose. After the first encounter, the degree of undress was often left to the patient to decide.

Unlike the clinic or hospital the proxemics of the encounter were not fixed. Students had to choose where to sit. Said one unusually perceptive student:

The difference in control was most apparent when I had to choose a position in the house, like choose a chair. The whole issue of where one sat had implications for who would control the conversation. When someone comes into your office, by definition you are behind the desk and the patient sits in the chair

Thus, students had to decide how to structure the encounter almost immediately upon entering the patient's home. The decision affected the gathering of medical information and communication. If a student chose to sit across the dining room table from a patient where he could maintain eye contact. he then had to stand up and move around to do the exam. Sitting beside the patient was awkward for communication. Sitting at the head of the table was most conducive to the interview but implied a social position with which the student felt awkward.

Time was another issue which was negotiated. The length of the encounter was especially difficult to determine for the students. Students felt the mixed nature of the visit. medical in purpose but social because it took place in the home, required that they observe socially appropriate timing, both in overall time spent and in the intiation and pacing of the physical exam.

The negotiations over timing tended to be silent. as did the decision concerning degree of intrusiveness. Students found it extremely difficult if not impossible to perform any kind of intimate, intrusive examination. No students performed a rectal on their elderly male patients, even though it was medically indicated. Several students who started the clerkship with the intention of doing very thorough workups including rectals, remarked that they "-just hadn't gotten around to it", but they would be sure to put it in the notes for the next student to do. One student commented:

I became less inclined to do something intrusive, to say would you take off your clothes so I can examine your testicles and do a rectal", even though both of my patients needed it. Instead I began focusing on problems they identified as important.

I observed only one pelvic exam and that was performed at the insistence of the patient. Although decisions concerning intrusiveness were rarely discussed. painful or uncomfortable interventions were frequently debated. Some patients protested over the frequent and sometimes inept blood drawings, the urine and fecal samples, the function tests. Often compromise agreements were struck.

Although they did not obtain enough of a certain specific kind of information, they gathered much more information concerning the patient. A key area where a perceived loss of control was experienced was in the intrusion of non-biomedical factors into the medical encounters. In the clinic and in inpatient settings the physician can choose the amount and nature of this information which he wishes to incorporate into his data base. Such selectivity was not possible in the home. Entering into the patient's life, which these visits both allowed and forced upon students, made them witness to, and often participant in, the ongoing common concerns of living with chronic illness and the chronically ill. Said one student who did not enjoy this intimacy.

In the hospital environment you have social problems where you want them-you don't have to deal with them. There is no social; there's no family situation you have to deal with. Whereas at home, there are all kinds of interactions that you really have no control over.

The home context provided two main elements not readily accessible to students in other settings or in different aspects of their training: a rich and detailed source of information concerning the patients' adaptation or accommodation to chronic illness, and participation in the patients' lives which made possible both a complex and intimate understanding of the patient as well as an often satisfying emotional experience for the student.

Chronic disease, is characterized by nonreversible pathologic processes, an indeterminant duration, and a profound interaction of biologic and social factors. (I do not suggest that acute illness is without a social component. However, social and envirommental factors, unless of etiologic importance, receive comparatively little weight in the biomedical acute disease paradigm.) The significance of psychological, environmental and social variables in both the etiology 
of and adaptation to chronic disease has been well established [9-13] and may, in some cases, be as important as the disease itself in determining outcome [14]

The information provided by the home context is relevant to two singular aspects of chronic illness, its chronic, i.e. long term nature and the multi-causal nature of its symptoms. As one student said:

Just seeing a patient walk in and out of an office room who had trouble walking, you don't really get the full impact of what that means of their life, all you see is how they come into the room and sit down and walk out.

Within the carefully structured context of the clinic or hospital where only information immediately relevant to the acute situation is sought and attended to, understanding the meaning of the illness for a patient's life and the lives of his family is difficult indeed. When students spoke of developing a "gut level' appreciation for chronic illness, what they meant was an understanding of the constraints it imposed on life. This understanding was often vivid, highly subjective and intense. One student characterized it this way:

It's the little things; the things you'll never forget. like walking into Mr S's house and there's that horrible smell, and realizing there's nothing he can do about it. He's talked about it before. 'I married her and I thought her housekeeping would get better, but it's gotten worse', he told me. Now I understand his position. He could tell you that in an office and you'd never understand, but I understand-boy, do I understand!

Experience in the home often demonstrated in a sharp and concrete fashion the interaction of social, psychological and environmental factors with the disease process. One student described this experience:

It was a real eye-opener for me to realize the thing giving Mrs C. her breathing attacks was the problem with her VA checks and not her disease process. If I'd monkeyed with her meds, as I'd planned, I could have made her condition much worse.

In the home the students obtained much more information concerning both items the patient felt it important to actively express and data vested in the patient's context which bespoke individual strengths, weaknesses, obstacles and inventiveness of each patient's adaptation to his illness. This information was passively communicated simply by the student's presence in the home.

There was surprising unanimity in the students' response to this change in both patterns of communication and in the amount of information they obtained:

It's strange how much power you have over patients in the hospital. You can tell them what to do and they let you do anything to them. In the home the patient has control, you must ask them and get permission.

In the home the patients are more in control than I am. In the hospital I could do to them what I wanted. The patient is sort of a captive in the hospital. Here I had to adjust to what they really did.

The main difference is the power structure. When you visit them in their home, it's their turf, they are in control. You have to recognize their territory.
When you are in the home, you are completely alone. You don't feel the same kind of immunity that you do when you handle them (the patients) in the medical center.

'Loss of control' in the home reflects a fundamental aspect of medical practice, the loss of a context designed to facilitate physician control. The loss of a context previously seen as integral to the medical encounter and the subsequent need to fashion a new context left many students aware of the relations of power inherent in the clinical or inpatient context. In part what the students were objecting to was the loss of a context designed to concentrate the focus of the encounter on the patient's biological dysfunction. In the clinic all extraneous information not immediately relevant to the task of diagnosis, treatment and cure is excluded. Communication is focused on the narrow task of gathering data relevant to diagnoses and cure. In this context, the patient becomes the disease, hence, the evolution of the medical slang. 'my liver cancer' or 'the appendectomy in room 3' used to refer to a physician's patient. To effect this reduction of another individual to a single biological entity or problem (or complex of problems) requires structures which both create a distance between the patient and physician and limit the amount and kind of information available about a patient. Such control also enhances the physician's power over the patient. This power contributes to the expert authority of the physician which, it can be argued, is exercised on the patient's behalf. It also may serve the less altruistic goal of disguising the physician's own uncertainty. This approach to the treatment and cure of acute illness has been successful; and the physicians have believed themselves justified in treating patients as 'captive', in 'handling' them for their own good, like a broken machine. The 'facts' of a particular case can be established by the physical history and exam and the laboratory test. The subjective and highly individualistic nature of other aspects of a patient's life make it difficult for physicians to integrate these data into their diagnostic schema where indeed it may not be appropriate for the treatment of acute problems. For, according to the acute model logic, information not directly relevant to the immediate problem can be excluded safely. However in the care of the long term chronically ill patient, one can not always know in advance what the relevant information is.

Information has been defined as data which make a difference [15]. The clinic context provides the machinery which actively excludes information extraneous to the task of diagnosis, treatment and cure. The power to excluded some information gives the physician control over the information with which he is faced and must deal. The home context in contrast includes the information about the patient, his life and his adaptation to the disease which the clinic excludes and which may be relevant for the long term management of the disease. The physician lacks the power to exclude that information and thus to control communication between himself and the patient. Even if we adopt narrow medical criteria for distinguishing between the plethora of data and the medically relevant information found in the home, considerable information is clearly available there. The placement of furniture which can tell us about 
cardiac status. the location of the phone can provide indications of mobility. smell is an indicator of incontinence-all this is medical information. No matter how narrowly information is defined. it is abundantly present in the home. Thus, a large portion of the loss of control is due to this additional information found in the home context.

The following case studies will illustrate the students' experience:

\section{Vo. 1 Louise}

Louise was a 26 year old student planning to specialize in family practice. She acquiesced least to the home environment. With considerable success, she sought to establish and maintain clinical control within the home. Louise set the tone of her encounters by addressing her elderly patients by their first names, something no other staff member or student did. On her first meeting with an 80-year-old man suffering from chronic obstructive pulmonary disease (COPD) she found a chair and pulled it up to the bed without it being offered and began a long and extensive systems review despite the fact that the patient was obviously having a great deal of trouble breathing. This ritual was repeated on each visit. If other people were present, Louise directed her questions to them rather than the patient who was completely alert. For example, when a grandson was present Louise asked. "Do he and his wife eat together?" "Ask him", replied the grandson; whereupon Louise dropped the matter. When she wished to discuss the patient's status or to consult on medications with the pharmacy student, she lowered her voice to a medical stage whisper, clearly audible to the patient.

Throughout the interviews she maintained her focus on strictly medical problems. When the patient asked for support the response was medical:

Patient: Why don't you say something about my lungs? Louise: They are about the same.

Patient: Well. I expected that. Why don't you say something supportive?

Louise: We can't do anything about emphysema. We can about bronchitis. If you take your drugs and drink water to cough up the phlegm, we can help the bronchitis.

Although she would not be drawn into recognizing the patient's request for reassurance, compassion and empathy, later she acknowledged that this exchange had been especially difficult for her:

I had a harder time talking to him this time. I don't know if it's him or me; I'm depressed. He makes me depressed.

But she quickly regained her control by searching for a medical explanation for the troubling encounter. "There's nothing to suggest heart failure", she went on, except that he's gaining weight. It's hard to judge his symptoms. As far as living conditions there is nothing you can offer him when you see his emotional status. I'd like to do more for him physically. In not sure there is anything else to do for him".

Restricting her gaze to the purely biomedical aspects of the patients sometimes led Louise to miss significant information. In the following dialogue Louise ignored the crucial datum concerning the patient's sudden weight gain.

Patient: The more I try to get away from salt. the more I get. My wife gives me peanut butter with salt. I am afraid I'll have to go to the hospital to get salt-lree food

Louise: Are you having trouble with vour urine?

Patient: No. but it's uncomfortable. But what worries me is about the salt.

As it turned out, long-standing animosities between the patient and his wife had become exacerbated by his homebound condition and the wife was seeking retribution by giving him a high salt diet, while he was helpless to do anything about it.

Throughout the clerkship Louise was concerned with maintaining control. When another patient jokingly reminded her how shocked she had appeared by the patient's condition when she had first met her. she became exceedingly flustered and denied being upset. "That isn"t true, that isn"t true". she repeated insistently. The transparency of her emotions was threatening to her composure, for, in fact, according to our interview after that visit she had been extremely upset. In evaluating the Home Care clerkship Louise singled out the threat to control as the major upsetting factor in it:

Mrs E's wanting to maintain control over her exams was frustrating to me and threatening. I don't think it was particularly an ego thing. But I think to be effective you have to maintain a certain amount of discipline and control in the situation. I felt sometimes I was lacking control.

Louise managed to contain her relationship to her patients within the limits of biomedicine. She restricted her compassion to their physical problems about which she could possibly do something, thus she commented that she was "... exceedingly sorry for my patient's physical condition and so forth". Anything beyond the straight physical she judged to be spiritual problems and suggested her patients read the Bible. Consistent with the limitations on the aims of her interventions, she restricted the information she sought from the home to that directly relevant to physical status and she was not impressed with its quality, which was "... not necessarily the same as someone coming into your office but the differences were not necessarily broad ones".

Louise's behavior would not be the least remarkable when viewed in the context of the clinic. Yet she was noteworthy among my informants because hor struggle to maintain control and professional authority led her to block out much of the information and influence of the context and to emerge with a singularly neutral if not somewhat bothersome experience.

\section{No. 2 Arthur}

Arthur was a 29 year old student who had planned to specialize in oncology. He shared the medical profession's lack of enthusiasm for treating the chronically ill. Initially he commented:

I don't like dealing with the chronically ill. When I see a patient I like to be able to make a difference. to tix someone, to cure. But to just wait around for an acute episode is a waste of time.

His sense that there was nothing 'medically' to do for the chronically ill except when they experienced an acute exacerbation underlies much of the frustration experienced by my informants. His alienation went 
deeper. for he perceived treating the chronically ill as a threat to his skill:

When taking care of someone who is chronically ill, you can t help but make a mess sometimes. It's tass to overlook a problem. You get sloppy in your exams, doing them every week. it breeds mistakes. If I had a hundred patients like Mrs P.. I'd be a lousy doctor in a year

It would seem. following his apparently reasonable concern that his skills and expertise would get rusty if not practiced and his statement that "... someone else should take care of the chronically ill. not the doctors", that his patients suffered from simple, uncomplicated, unthreatening complaints. Ironically, among his patients were some of the most acutely ill on the program. One woman recently discharged from the hospital suffered from eighteen different medical problems for which she took sixteen different medications. Yet the considerable expertise and competence required to adequately follow and manage such a patient and to prevent rehospitalization did not qualify as either sufficiently challenging to maintain his skills or worthy of his expertise. Forty-four percent voiced similar attitudes initially.

This sense that there was nothing for him to do or that it could be done by "someone else, not a doctor", changed fairly quickly for Arthur as he became overwhelmed by the complexity of his patients' lives. For the first few wecks he resisted acknowledging this complexity as a legitimate concern of medicine. After two visits he commented:

The goal of home care visits is not to examine chronic illness. but (should be seen) in terms of the patient's needs. It's different than treating chronic illness. There's sort of a hidden agenda there in terms of what you have to do for the patient.

This clear distinction he drew between treating chronic illness and patients' needs was eventually broken down.

Within the initial period of the clerkship, Arthur had tried to maintain clinical control with his patients. He would insist the patients or their children turn off the TV during his visits. A tall man, he towered over his patients and maintained this distance by never sitting near them but instead bending down to examine them. Whenever possible, he directed his questions to others rather than the patient. He tried to ignore the social turmoil which swirled around him in one patient's home. His aloofness caused considerable anxiety for it was interpreted as resignation to the hopelessness of the case.

By the third visit Arthur's assessment of the key problems had begun to change and he remarked that .... anxiety is the most common cause of what Mrs W. suffers from". On the fourth visit Arthur walked into Mrs W.'s home and she greeted him saying, "Give me a shot to kill me, doctor, I don't want to live anymore". Then the fight which she and her daughter, the main caregiver, were having erupted with him in the middle. Arthur stood there. his hands raised towering above the two women and watched helplessly as Mrs W.'s breathing became worse and worse.

Arthur then came to appreciate the intense emotional, social and psychological problems engendered by caring for a very, very sick parent in a small home with two young children and an infant. Arthur acknowledged that these strains exacerbated Mrs W.'s precarious condition, but his response was one of helplessness. "The most important factor seems to be her emotional, her life situation, which I really don t think we can fix". This sense of being overwhelmed and helpless led him to stop doing even what he could do which was to monitor the patient's status and care for her surgical wounds. Crippled by a sense of medical futility, he allowed a problem to pass which resulted in a medical crisis, but one which other staff were able to catch.

With home care staff help, Arthur overcame his sense of being overwhelmed and assisted the family in developing a plan to care for Mrs W. at home, in getting some relief for the daughter and in arranging for Mrs W. to attend church.

In evaluating his Home Care experience. Arthur acknowledged the real value in learning to care for the patient and the serious limitations in his own education.

The emphasis in Home Care Program is probably where it should be in medicine. but where it's tenuous-caring for the patient... really caring for the patient - (emphasis his) that is what they try to do and it's really something that's been neglected for a couple of years in my medical education. You can't teach it with a lecture course or seminar. you have to teach it with patients.

He then added "... medical schools produce doctors like me". Arthur informed me later that. recognizing his limitations with 'the social thing'. he had decided to change to a specialty not involved in direct patient care like Intensive Care, Emergency Room or Anesthesiology.

\section{No. 3 Bob}

When Bob was asked what he had expected to get out of the clerkship, he had responded. "Myself, as soon as possible". In a more serious vein he went on to state "... my immediate bias is that I won't find it stimulating". During the first three weeks Bob focused purely on medical problems. An elderly male patient suffering from end-stage COPD tried repeatedly to get some reassurance or hope for himself and regularly asked Bob if he had a miracle with him that day. In the third week this exchange took place:

Bob: $\quad$ Give me a call if you need me.

Patient: I'm calling you now.

Bob: There's not a whole lot I can do.

After the visit he commented, "I'm going into radiology, medicine is too depressing". In the fourth week he responded this way to the patient's request:

Bob: If anything comes up call me.

Patient: What good can you do?

Bob: We can talk.

Patient: That would be moral support.

Bob: Sometimes moral support helps a lot.

In the car after the visit Bob commented, ${ }^{-} \mathrm{Mr} \mathrm{S}$. needs more P.T. (physical therapy) but what he really needs is time to talk about his problems". During the next three visits $53 \%$ of the exchanges involved non-medical topics, while the number of medical topics remained the same. This number remained fairly constant until the end of the clerkship. 
From this visit on Bob decided that he had -. . become familiar enough with $\mathrm{Mr} \mathrm{S}$.'s medical problems to relax a bit and concentrate on his non-medical problems". He even felt it was appropriate to just "shoot the breeze". While Mr S. occasionally still asked for miracles. his anxiety dropped noticeably. He explored with the young physician new areas for his treatment about which he had read. One topic discussed was a form of oxygen therapy, new to the student, which was later integrated into the therapeutic regimen.

By the sixth week Bob was developing a warm personal relationship with his patients, inquiring into their dreams, fears and memories as well as following their medical problems. After this set of visits he discussed his attitudes towards his elderly patients. In the initial interview he expressed the view that working with elderly patients was ". . . like pediatrics, just talk to them nicely" and that the elderly "... put themselves in that position by being dependent, like kids". By this point in the clerkship his views had changed significantly:

There is a lot of strength in our patients. They are very proud. A lot of elderly people have great pride but it's broken down by the way society treats them. Illness also breaks down pride. Patients in the hospital are infantilized. The nice thing about home care is that you can get therapeutic value without the infantilization.

Bob, like $66 \%$ of the students, was able to integrate attention to the non-medical problems of his patients with the direct medical care he provided. I will quote at length from his analysis of the experience because it reflects both his profound change and the integration of the information which he gained into his orientation toward chronic illness:

This clerkship has provided me with a more gut feeling of what chronic illness is rather than previous ones that were more intellectual. You can know that a patient is chronically ill and take care of them and keep them in the hospital but you never really get the gut sense of what it's like for this person to live in their home or wherever with a chronic illness, so I think it just changes my perspective from a purely intellectual one to a more gut level one.

He then went on to discuss more specific implications for his training:

The long term prognosis in very sick patients comes up more acutely in Home Care. A lot of times you see patients in the hospital and you know they are not very healthy in general and your goal is to get them out of the hospital and once you get them out of the hospital, even if it's to a nursing home, you feel there is some degree of success there and you also don't really have to confront the issue of long term prognosis head on... (in Home Care) there is much more of a need to address somehow, in your mind, what the long term prognosis is.

Despite his initial cynicism, Bob ended his seventh visit having developed strong ties with his patients. This experience was not, however, easily acceptable to him. Bob avoided his final visits with his patients, stating that he did not really need to see them. He added he would try to call them and say good-bye, but they would be getting a new student next week so it probably did not matter. He was one of two students who avoided this last visit.

\section{No. 4 Diane}

Three of the students concentrated on the patient's social and emotional problems as their response to being overwhelmed by the experience. Uiane, a 27 year old student, was planning to enter surgery. She was definitely unhappy about the upcoming clerkship. She told me:

I don't enjoy working with chronic illness. I like to confront a goal and accomplish it. I've never worked with adults and chronic illness before. I just can't see getting into adult chronic illness. It's not intellectually interesting to me.

After two visits, her attitude had changed dramatically:

My idcas of illness have changed since coming on Home Care. I went back to see Jimmy (a thirty-year-old Muscular Dystrophy patient) for the second time today. I went in very cheerily like you do with a patient in the hospital when you know they'll get better. Then I had to stop and get control of myself. I realized nothing had changed. That the room was exactly the same, that Jimmy was exactly the same, lonely and sick, getting sicker. I his is a different kind of illness than I'm used to.

By the fifth visit, Diane had moved to completely focusing on her patient's non-medical problems. About an extremely ill but very articulate diabetic woman who was going blind, losing any sense of touch, had severe digestive problems, and was recovering from a 4-month hospital stay because she had broken both legs simply by standing up, she commented, "It's not necessary to check her over very closely because she's such a damn good historian".

Diane enthusiastically made plans to get this patient into a swimming program, get a lift for the bath, find a way for her to learn Braille and to consider a new physical therapy program. These were the concerns which the patient had identified as most important and Diane worked with her to realize them. When the patient's blood sugar level hit 744 , the medical director had to caution Diane not to get so involved in attending to social problems that the diabetes, "sneaked up and hit her from behind". Indeed, Diane did feel that although the patient suffered from brittle diabetes, "...99.9\% of her problems were people problems". Realizing the significance of the non-biological in chronic illness, Diane went to an extreme and developed a kind of medical nihilism. She came to feel that medical interventions could do little to help her patient and in fact they might just increase her suffering. Through her involvement in her patients' lives she developed a deeply satisfying emotional attachment to them. She ended the rotation deciding to switch her special. ity to family practice. In her evaluation she stated:

I thought I was going to learn a lot about diabetes. I learned a lot more. This is very corny, but I learned a lot more about how you really have to look at the whole person because in fact diabetes is the great problem in P's life, but it was such a minor part of the last eight weeks. It was dealing with how it had limited her which I wasn t expecting.... I really enjoyed the emotional aspects of the relationships which formed. It's sad in the other extreme though, because you see people with illnesses that have altered their lives drastically. It makes you real thankful you don't have something like that. 


\section{DISCLSSIOY OF CASE SILDIES}

By relinquishing the control associated with physician-patient communication in the clinic, the medical students gained access to considerable information about the patient. For $55 \%$ the increase in the information also served to create the basis for a more intimate personal relationship than is often possible in the traditional settings for medical care. Integrating the new information into the data base. reconciling their expanded understanding of the patient and his problems with the narrowly defined goals associated with the acute care model of medical care was a challenging task, exciting some. overwhelming others.

Arthur was uncomfortable and often upset throughout the clerkship. He commented that it was not quite as bad as castor oil, but almost. The numerous exogenous factors which confronted him in the homes of the patients which he could not dismiss forced him to reconsider his definition of medical efficacy. The experience confirmed for him that he was not suited for and therefore should not seek direct involvement in patient care.

Bob began cynically and ended denying his experience. Yet during the course of the clerkship, within the actual encounters his responses to patients were some of the most moving ones observed. He allowed himself to be drawn into the patients' world far enough to be able to offer real support and assistance to them. He did this in a way that was both professional and sincerely empathetic. This was a complicated and stressful development. Having relinquished the traditional controlled interaction he could not resolve the resulting conflicts between intimacy and distance and in the end opted for denial.

Diane finished the clerkship with serious concerns about the proper role of medicine. Her decision to abandon surgery resulted in part from these doubts. But the questions raised within the clerkship about the efficacy of traditional interventions were not resolved.

For Louise the experience was tense and frustrating. She struggled continually to restrict the interactions to those appropriate to the clinical context. She utilized rigid structures such as name and space differentiation to maintain control. When the plight of her patients did penetrate, she separated it out from the illness and attributed it to spiritual malaise.

The change in attitude was gradually manifested in student behavior as most $(77 \%)$ came to acknowledge that control over the encounters was vested in the patients. Students brought to the initial encounters the practices and methods of control and objectification characteristic of clinic and inpatient settings. Many students initally called patients by their first names, regardless of age and circumstances. They appropriated the private space of the patient by electing to sit before being asked, by looking for and using the sink to wash their hands without asking directions or permission and by searching through and sometimes disrupting the arrangement of medications. They further sought to sustain the clinical context by intending to conduct extensive physical exams and by developing what they deemed medically appropriate treatment goals such as changes in medication. reduction in angina attacks, increased mobility. specialist consults and improved nutrition.

Within 2-3 weeks, $77 \%$ of the students had changed their behavior in the encounters. Many had changed the mode of address in compliance with patients stated or implied wishes. Some began asking where to sit and a similar number ceased handling the medications without permission. Sixty-six percent changed some or all of their treatment plans, acquiescing instead to those set by the patients.

By the fifth or sixth week. $55 \%$ of the students had developed a more intimate personal relationship with their patients than they were accustomed to. Relinquishing control of the encounter and the normal objectification of the patient in many cases led to an acknowledgement of the patient as an autonomous, complicated individual. A kind of equality emerged often marked by reciprocity. The reciprocity was both material and conceptual. Students accepted, although at first reluctantly, patients' hospitality, their offers of orange juice, tea or home-made wine. Students reciprocated with information concerning their personal lives. Although the non-medical content of the encounters increased, this did not usually reflect a reduction in the medical content. Instead, the student could both treat the patient for the medical problem from which he or she suffered and respond to the patient as another individual whose life extended far beyond the narrow confines of the medical encounter.

During the last two to three weeks, $66^{\circ} \%$ of the students attempted to intervene in the nonbiomedical problems of the patients. One student, not Louise. characterized her change this way:

When I first met Mr S. I was most concerned with the COPD. Now I am less concerned with his Alupent inhalers and his Tributalene than I am about getting his dentures fixed and getting Mrs S. to stop putting salt in his food.

In numerous ways students sought to address the problems and needs which the patient had identified as key and which they had come to assess as having an impact on the patient's health status. Whether it was something close to medicine such as nutrition or something more removed like a new kitten to replace a much beloved cat which had been a patient's only companion, or assistance with the VA in securing income for a patient, students tried to be of help. Where they felt the actual intervention was beyond their area of competence, as it often was, they sought referrals.

An examination of age (26-39, mean 31.5), future specialty (four internal medicine, three each in surgery and pediatrics, two in family medicine and one apiece in various other specialities) or sex (10 men and 8 women) does not help account for the experience of 'loss of control' and the change in attitudes. Sixty-one percent of the medical students articulated a sense of loss of control; of these all but one experienced significant changes in their attitudes toward chronic illness and its sufferers. Altogether, $77 \%$ experienced a change in attitude toward a more positive evaluation of caring for these patients. For $48 \%$ of this group the change was dramatic for they began the clerkship articulating negative attitudes about the prospect of caring for the elderly chronic- 
ally ill patient Seventy-one percent of this group were men. Out of those who experienced change and who had initially stated negative attitudes four $(25 \%)$ also considered changing their specialty. These four were among those who felt overwhelmed by the experience. Another informant considered changing specialty but from a positive motivation of concern for and interest in the elderly.

\section{ANALYSIS}

To some extent the sharpness of the experience of loss of control can be attributed to the informants novice status. But more significant. is the fact, as $28 \%$ of the informants commented, "in the home you are on their (the patients') turf". The roles of physician-guest, patient-host were intermingled. In the home setting. on the patients "turf", the structure of guest-host eventually predominated in most encounters. This dynamic was sustained by other guest-host similarities. The physician came to the house: the patient or his representative gave the physician access. Pleasantries were in order in the initiation of each visit. Leave taking also conformed to guest host rituals. The physician-guest left and in so doing had to participate in leaving taking, i.e. establishing the next visit, some transitional discourse after the purely medical interchange was finished, responding to the patient's moves to prolong the visit, not in an authoritarian way but in a socially skilled manner. The abrupt, of ten superficial nature of clinic interaction seemed extremely rude when students in the beginning of the clerkship tried to initiate it. Because communication is shaped primarily by culturally derived roles and statuses [16], in the home the more accessible and familiar social rules establishing the communication patterns of the guest-host relationship are sustained while those of physicianpatient recede. Lnderlying basic conversational rules such as, "who is free to ask questions"? which Mathews [8, p. 1372] argues are dictated in clinical settings by professional roles and ideologies are modified in the home by the guest-host relationship. This in part explains the greater availability of information, the presence of which the physician experiences as "loss of control".

The uniform and explicit articulation of loss of control could lead to the erroneous conclusion that these were unusually articulate, well educated, assertive patients. Such was not the case. The patients did not actively seize the control the students "lost". It was not that the students felt the patients forced them into more communication, into answering more questions, providing fuller more easily understood answers; it was rather that as a guest it would have been impolite not to maintain their part in a social discourse. Separated from the symbols and context of the clinic setting. the students relinquished control because they could not individually exercise it in the home setting without appearing rude and disrespectful. Patients who would have tolerated such behavior in the clinic, and did according to observations, were noticeably offended in their own homes. Thus. the dynamic of control and hence the locus of power became interactive. It was vested in the guest-host relationship which was modified to fit the requirements of the medical encounter. For instance. the guest could request the host to remove his shirt, but the guest drew his own limits in requesting rectals.

Once the guest-host dynamic had been accepted as the structuring principle for the visit, other significant changes in the traditional medical encounter pattern transpired. In addition to the introduction of reciprocity which was already noted, a multi-faceted relationship between physician and patient emerged. This occurred in part because without the power relationships of the clinic through which the patient could be "controlled", students were forced to develop a more complicated socially appropriate approach to encourage patients' compliance with their medical regimens. Said one student:

Home Care is a whole different ball game. You're in their home, on their turf and it's difficult for you to dictate to them ... the result is if you want to accomplish anything you are forced to develop a more significant type of rapport with the patient. You can't just get away with the surface gloss that you frequently get away with in the inpatient setting or even in a clinic.

Ironically, although this appeared to be the result of the home setting, compliance actually does relate closely to the nature of communication between physician and patient regardless of the setting [8].

The increased communication which students perceived as necessary to accomplish their medical goals in the home also brought with it more information about the patient's condition. Remarked another student:

When you deal with patients on their own terms they seem more compliant, more willing to listen, the interaction seems more complete in the sense that you can more freely engage with the social as well as the medical aspects (of the patient).

This increased information served many purposes and ultimately contributed to the change in attitude. Understanding the patient's adaptation to the disease, the daily monotony and struggle of living with a serious disease, led students to appreciate the wisdom in the patient's adaption and to question the standards which suggested procedures not sensitive to individual needs. One student was particularly impressed by this awareness.

I learned to ask myself, "why do we want to do this test"? or "what are our goals"? and that sort of thing. Rarely are goals discussed in a hospital setting, it"s clear. it"s tacit, and that wasn't the case here. I really had to think about it. This person has had this disease for so long; they have had these treatments, and what is realistic? and what is in their best interest, psychologically as well as medically.?

Although $22 \%$ were overwhelmed by the complexity and pathos of those living with long term disability, $48 \%$ were intellectually challenged by the complexity. Rather than perceiving chronic illness as frustrating they saw the progress of the disease as intellectually interesting. At the close of the clerkship Bob commented:

In the hospital. I treated people with three different problems and l'd write daily or weekly orders for them while they are there. but the full impact of those three problems never really hit me betore. It wasn't intellectually interesting before starting these eight weeks. 


\section{CONCLLSION}

The home context provides two main types of information not generally available to physicians in the clinic. There is the information in the context which the physician passively experiences. This information concerning the patient, his life and adaptation to the disease is actively excluded from the clinic setting. There is information which is gathered through the interactive host-guest relationship. It is the information included in the setting and interactions of the home which accounts for the physician's loss of control-a control over information and hence communication which the clinic setting helps to facilitate. Not all loss of control, it must be noted, transpires from the inclusion of additional information. In the home it is the patient who knows the setting, and the rules of the setting. The physician is the disoriented intruder who must ask where the bathroom is and permission to use the phone. (Of course this interaction also provides information because the physician confronts a larger sense of the patient.) What is crucial in the home context is that the physician loses control over communication but this also allows him to gather additional information. Such information may be the key in the long term management of the chronically ill. To be sure there are areas where the access to information is restricted by the home - no rectals were given. Although the information provided by a rectal exam is clearly important, its saliency in the project of long term management of chronic illness is less than that of the information concerning the addition of forbidden salt to food, the presence of health inhibiting stressful relationships, or evidence of incompetent care taking, i.e. rectals may provide evidence of acute problems of exacerbations of these problems, not management dilemmas or conflicts.

Waitzkin and Stoeckle have argued that, "Information transmitted from physician to patient by reducing the patient's uncertainty, also reduces the physician's power within the doctor-patient relationship" [17, p. 189]. I wish to argue further that an increase in the information transferred from patient to physician where the patient structures the information, i.e. it does not consist of test results, also reduces physician power because it increases the physician's uncertainty. When it is clear to the physician, if not to the patient, that the problem is far more complex than he is capable of easily handling, his perception of his control is reduced. It need not however, increase frustration, as Parsons argues [18]. In the case of chronic illness uncertainty is the more realistic approach and acknowledging the limits of medical power and the inherent uncertainty of the prognosis and treatment may both allow for more non-standard yet perhaps valuable information to be gathered and restructure the nature of interventions. Importantly, it may also increase physician respect for the patient's self-knowledge and the role that information could play in treatment. As one informant said:

Initially I was just afraid of the frailty of these patients These people are not as frail as I thought they were going to be. They certainly are not frail people. They are not as frail physically as I thought and they certainly are not frail emotionally or spiritually. Although $\mathrm{Mr}_{r} \mathrm{G}$. is a needy person, there is a lot more strength there than I initially thought. I guess I was really worried about touching him in a place where the strength was not. inflicting some sort of emotional pain. I did not give him credit for having that sort of strength. I guess I thought that I had more power or more influence or whatever to inflict pain on him than I do. He s resiliant; he's been through a lot of stuff in the past. To think I had that much influence is naive.

This experience of loss of control and the subsequent interventions which lead from it, was so at variance with traditional medical self concept, however, that $33 \%$ of the informants felt they were not acting as physicians. This is somewhat ironic given how extremely ill their patients were. It appears that a narrowly controlled context where the notion of therapeutic efficacy is sustained symbolically if not in reality is an essential part of professional identity. If so, it will be difficult to improve physician-patient communication when to do so implies a reduction of physician control.

\section{REFERENCES}

1. Quint J. C. Institutionalized practices of information control. Psychiatry 28, 119-132, 1966.

2. Cicourel $A$. Language and medicine. In Language in the U.S.A. (Edited by Ferguson C. A. and Health S. B.), pp. 407-429. Cambridge University Press, New York, 1981.

3. Cartwright A. Human Relations and Hospital Care. Routledge \& Kegan Paul. London, 1964.

4. Parsons T. The Social System. Free Press, New York 1956.

5. Waitzkin $\mathrm{H}$. and Stoeckle J. Information control and the micropolitics of health care: summary of an ongoing research project. Soc. Sci. Med. 10, 263-276, 1976.

6. Fox R. C. Training for uncertainty. In The Student Physician (Edited by Merton, Reader and Kendall). Harvard University Press, Cambridge. 1957.

7. Emerson J. Behavioral in private places: sustaining definitions of reality in gynecological examinations. Recent Sociology No. 2.

8. Mathews J. The communication process in clinical settings. Soc. Sci. Med. 17, 1371-1378, 1983.

9. Berkman L. Physical health and social environment. In The Relerance of Social Science for Medicine (Edited by Eisenberg L. and Kleiman A.), pp. 51-77. Reidel, Dordrecht, 1981.

10. Farmer C. J., Bewick M., Parson V. and Snowden S. A. Survival on home haemodialysis: its relationship with physical symptomatology, psychosocial background, and psychiatric morbidity. Psychol. Med. 9, 515-523, 1979.

11. Hill C. Differential perceptions of the rehabilitation process: a comparison of client and personnel incongruity in two categories of chronic illness. Soc. Sci. Med. 12, 57-63, 1978.

12. Syme S. L. Behavioral factor associated with the etiology of physical disease. A social epidemiological approach. Am. J. publ. Hlth 64, 1043-1045, 1974.

13. Syme S. L. and Berkman L. Social class, susceptibility and sickness. Am. J. Epid. 104, 1-8, 1976.

14. Yellin E. et al. Work disability in rheumatoid arthritis: effects of disease. social, and work factors. Annls intern. Med. 93, 551-556. 1980.

15. Cherry C. On Human Communication. MIT Press, Cambridge, 1978.

16. Goodenough W. H. Rethinking 'status' and 'role': toward a general model of the cultural organization of social relationship. In Cognitive Anthropology (Edited by Tyler S. A.). pp. 311-330. Holt, Rinehart \& Winston. New York, 1967 
17. Waitzkin $\mathrm{H}$. and Stoeckle J. The communication of information about illness. Adt. Psychosom. Med. 8, 180-215. 1972.
18. Parsons $T$. Some theoretical considerations bearing on the field of medical sociology. In Social Structure and Personality. Free Press, New York. 1964. 